\title{
Temporal change of near-surface shear wave velocity associated with rainfall in Northeast Honshu, Japan
}

\author{
Yu Miao, Yang Shi and Su-Yang Wang ${ }^{*}$ (i)
}

\begin{abstract}
We apply seismic interferometry to earthquake records to investigate temporal change of near-surface shear wave velocity associated with rainfall in Northeast Honshu, Japan. We observe there exists a threshold (around $100 \mathrm{~mm}$ of $24 \mathrm{~h}$ rainfall total) of the temporal influence of rainfall on near-surface shear wave velocity. The velocity does not change significantly under low-intensity rainfall, while it is reduced by $1-3 \%$ with one exception of $10 \%$ when the rainfall intensity exceeds the threshold. Compared with the travel time of no rain, the travel time increment of lowintensity rainfall is no more than $3 \times 10^{-4} \mathrm{~s}$, while that of high-intensity rainfall ranges between $10^{-3}$ and $10^{-2} \mathrm{~s}$. Based on the results of observation, we propose a one-dimensional model to compute the travel time increment, which can give a preliminary estimation of the temporal influence of rainfall on near-surface shear wave velocity.
\end{abstract}

Keywords: Earthquake ground motions, Seismic interferometry, KiK-net, Rainfall

\section{Introduction}

Near-surface shear wave velocity has been recognized as an important mechanical parameter in the fields of earthquake engineering and geophysics. It has a wide range of application such as classifying site classes (Borcherdt 1994), evaluating liquefaction potential (Ahmadi and Paydar 2014) and estimating local site response (Choi and Stewart 2005) for seismic design of buildings, structures, and underground utilities (Lee et al. 2014). And its relevance to evolving stress and effective rheology at depth for seismic monitoring of faults (Hillers and Campillo 2016; Wegler and Sens-Schönfelder 2010), volcanoes (Brenguier et al. 2014; Wegler et al. 2006), landslides (Mainsant et al. 2012; Pilz et al. 2014; Xu et al. 2017) and hydrocarbon reservoirs (Bakulin and Calvert 2006; Miyazawa et al. 2008) is well documented.

Hardin and Black (1968) expressed the shear wave modulus of soil as a function of eleven factors, mainly including effective stress, void ratio, saturation, strain history, temperature, grain properties and soil structure.

*Correspondence: suyangwang@whu.edu.cn

Huazhong University of Science and Technology, Luoyu Road 1037, Wuhan, China
And the shear wave velocity of rock can be influenced by porosity, fluid saturation, fractures, pressure and temperature (Toksoz et al. 1976). Hence the near-surface shear wave velocity is subjected to a variety of environment conditions, such as crustal stress, ground surface perturbation and atmospheric forcing. Many researchers have observed change of near-surface velocity caused by strong motion (Hobiger et al. 2012; Nakata and Snieder 2011; Niu et al. 2008), plate motion (Nakata and Snieder 2012a; Takagi and Okada 2012), volcanic eruption (Brenguier et al. 2008, 2011), earth tide (Hillers et al. 2015a, b), seasonal variations, including temperature, precipitation, groundwater level; sea level, wind and so on (Clements and Denolle 2018; Meier et al. 2010; Richter et al. 2014; Sen-Schönfelder and Wegler 2006; Tsai 2011; Wang et al. 2017).

Seismic interferometry is a powerful noninvasive tool to image the structure of shallow crust from earthquake records or ambient noise (Hillers et al. 2015a; Mehta et al. 2007; Obermann et al. 2013; Yamada et al. 2010). It is a technique based on the correlation of signals recorded at different sensors (or stations). For seismic vertical arrays, seismic interferometry is used to estimate the Green's function between two seismic sensors of vertical arrays 
and extract the travel time of seismic wave propagating between them. The near-surface shear wave velocity can be estimated by dividing the distance between two seismic sensors (borehole depth in this study) by the travel time. In most cases, the borehole depth ranges from tens to hundreds of meters (only few larger than $1000 \mathrm{~m}$ ), while the shear wave velocity changes within $6-8 \mathrm{~km}$ in the upper crust are considered by applying interferometry to station pairs at the surface. Hence, compared with applying interferometry to station pairs, applying interferometry to vertical arrays can obtain estimations of shear wave velocity with much higher depth resolution.

Many researchers (Hillers et al. 2014; Ohmi et al. 2008; Rivet et al. 2015; Sen-Schönfelder and Wegler 2006; Tsai 2011; Voisin et al. 2017) used cross-correlations of longterm ambient noise to investigate the seasonal change of average shear wave velocity in upper crust (free surface to several kilometers depth) caused by precipitation, and their results can be interpreted by hydrological models of crustal fluid pore pressure in upper crust or groundwater level. In contrast, in this paper, we focused on the temporal change of near-surface shear wave velocity associated with rainfall by applying seismic interferometry to strong motion data of seismic vertical arrays. The near-surface shear wave velocity is estimated between ground surface and borehole bottom with a depth of 100-200 m, and the temporal change occurs in the period that rainwater is penetrating through the top meters of the near surface right after the rain. For above differences, the study of this paper is necessary.

In this study, we apply seismic interferometry to KiKnet data to investigate the temporal change of near-surface shear wave velocity associated with rainfall based on earthquake and weather logging data in Northeast Honshu. Then we present the relationship between velocity temporal change and rainfall, and discuss the dependency of corresponding travel time increment on rainfall. Finally, we propose a one-dimensional model to interpret the temporal influence of rainfall on near-surface shear wave velocity.

\section{Data and method}

Strong motion and meteorologic observation net in Japan The Kiban-Kyoshin Network (KiK-Net) is composed of 697 vertical arrays with an uphole/downhole pair of strong motion seismometers. These arrays were built by the National Research Institute for Earth Science and Disaster Resilience (NIED) after the 1995 great HanshinAwaji earthquake. The depth of most boreholes range between 100 and $200 \mathrm{~m}$, and the depth of boreholes for 27 stations which are located on thick sediment is greater than $1000 \mathrm{~m}$. The sampling frequency of accelerograms was $200 \mathrm{~Hz}$ initially and has been changed to $100 \mathrm{~Hz}$ since 2008. The total length of the accelerograms is 60-300 s which includes $15 \mathrm{~s}$ pre-trigger data (Aoi et al. 2004; Okada et al. 2004).

In Japan, a nationwide meteorologic observation network, which consists of more than 1400 weather stations, has been operated by Japan Meteorological Agency (JMA) for over 30 years. Air temperature, wind direction and speed, precipitation, sunshine duration and snow depth are automatically recorded every $10 \mathrm{~min}$ at a majority of these weather stations.

\section{Rainfall intensity classification}

In this study, the rainfall totals within $24 \mathrm{~h}$ recorded at the nearest weather station of the seismic station before the earthquake event were chosen to be the representative of intensity of rainfall, while hourly totals are more commonly used to quantify rainfall intensity in many regions (including Japan, Europe and America). Comparing with hourly totals, $24 \mathrm{~h}$ totals have a more reasonable consideration of the process of rainfall infiltration in the top meters of the near surface to investigate the temporal influence on shear wave velocity. We also tested different accumulated periods of rainfalls (from $24 \mathrm{~h}$ to 2 weeks) and found that rainfall amounts accumulated over $24 \mathrm{~h}$ (i.e., $24 \mathrm{~h}$ totals) could balance the stability and resolution of the seismic velocity changes well (Additional file 1: Fig. S1).

According to rainfall intensity classification from China Meteorological Administration (CMA), $24 \mathrm{~h}$ rainfall totals are linearly binned into six classes in this study. The six rainfall classes and their corresponding CMA rainfall classes are given in Table 1. As we introduced before, the near-surface shear wave velocity is subjected to a variety of conditions (such as groundwater level, incidence angles of incoming waves, temperature, earth tide and so on). Comparing with a scatter plot of the single measurements of seismic velocity versus the rainfall intensity, the rainfall intensity classification is designed for producing an averaging estimation of the seismic velocity to

\begin{tabular}{|c|c|c|}
\hline \multirow{2}{*}{$\begin{array}{l}24 \mathrm{~h} \text { rainfall totals } \\
(\mathrm{mm})\end{array}$} & \multicolumn{2}{|c|}{ Rainfall classes } \\
\hline & This study & CMA \\
\hline 0 & Level I & No rain \\
\hline $0.1-25$ & Level II & Light to moderate rain \\
\hline $25-50$ & Level III & Heavy rain \\
\hline 50-75 & Level IV & Torrential rain \\
\hline $75-100$ & Level V & Heavy torrential rain \\
\hline$\geq 100$ & Level VI & Downpour \\
\hline
\end{tabular}


Table 2 Locations of the selected seismic stations and corresponding weather stations

\begin{tabular}{|c|c|c|c|c|c|c|c|}
\hline \multirow[t]{2}{*}{ Station } & \multicolumn{4}{|c|}{ Seismic stations } & \multicolumn{3}{|c|}{ Weather stations } \\
\hline & Lat. & Lon. & Alt. (m) & Depth (m) & Lat. & Lon. & Alt. (m) \\
\hline FKSH14 & 37.03 & 140.97 & 3 & 147 & 37.07 & 140.88 & 12 \\
\hline IBRH11 & 36.37 & 140.14 & 67 & 103 & 36.40 & 140.24 & 72 \\
\hline IBRH13 & 36.80 & 140.58 & 505 & 100 & 36.74 & 140.59 & 395 \\
\hline IBRH14 & 36.69 & 140.55 & 330 & 100 & 36.74 & 140.59 & 395 \\
\hline IWTH21 & 39.47 & 141.93 & 13 & 100 & 39.45 & 141.96 & 24 \\
\hline IWTH26 & 38.97 & 141.00 & 125 & 108 & 39.05 & 141.05 & 75 \\
\hline MYGH04 & 38.79 & 141.33 & 35 & 100 & 38.68 & 141.45 & 39 \\
\hline MYGH06 & 38.59 & 141.07 & 20 & 100 & 38.63 & 141.19 & 5 \\
\hline SITH06 & 36.11 & 139.29 & 80 & 200 & 36.11 & 139.18 & 128 \\
\hline TCGH10 & 36.86 & 140.02 & 203 & 132 & 36.84 & 140.04 & 188 \\
\hline TCGH16 & 36.55 & 140.08 & 105 & 112 & 36.61 & 140.00 & 148 \\
\hline TCGH17 & 36.99 & 139.69 & 635 & 104 & 36.92 & 139.70 & 620 \\
\hline YMTH03 & 38.10 & 140.16 & 278 & 114 & 38.12 & 140.21 & 270 \\
\hline YMTH07 & 37.90 & 140.03 & 352 & 200 & 37.91 & 140.14 & 245 \\
\hline YMTH14 & 38.39 & 139.99 & 465 & 103 & 38.39 & 139.99 & 440 \\
\hline
\end{tabular}

separate the temporal influence of rainfall from velocity changes caused by other variables.

\section{Station and record selection}

We used the earthquake and weather logging data to investigate the temporal change of near-surface shear wave velocity associated with rainfall in Japan. Fifteen seismic stations were selected for further study from 697 stations in KiK-net according to following criteria. The detailed locations of the selected seismic and weather stations are given in Table 2.

Firstly, in order to obtain enough earthquake records, Northeast Honshu (the main island of Japan) was selected as the study area because this area is prone to earthquakes. For each seismic station, we used more than 10 years of seismic records from the time when the sampling frequency of the seismographs is changed to $100 \mathrm{~Hz}$ to June 2017. The preliminary condition for a seismic station to be selected is to record at least 500 events.

Secondly, climatic character was considered in this study. In the study area, several prefectures, such as Aomori, Akita and Niigata, are located at the seaside of Sea of Japan. Due to the water vapor of the warm current in winter, it often snows heavily in these prefectures. To avoid the effect of snowfall, these prefectures were eliminated from the study area. As shown in Fig. 1, we only selected seismic stations from seven prefectures in Northeast Honshu.

Lastly, seismic stations should satisfy the requirement that the corresponding weather stations had recorded adequate high-intensity rainfall events. For a selected seismic station, the distance between seismic station and its corresponding weather station should be less than $20 \mathrm{~km}$, and the weather station should record at least two level VI events.

After station selection, because strong motion has an obvious impact on near-surface shear wave velocity (Takagi and Okada 2012), we then screened the seismic records for each selected station to eliminate the interferences of strong motion. For selected seismic stations, the effect of strong motion can be eliminated by the following two steps. We first selected earthquake records of weak motions with peak ground acceleration $(\mathrm{PGA})<50 \mathrm{~cm} /$ $\mathrm{s}^{2}$, and then removed records which were recorded in a period of time after strong motions with PGA $>200 \mathrm{~cm} /$ $s^{2}$. In this study, the influence time of strong motion depends on its PGA. Based on previous studies, for the strong motions whose PGA are between 200-400, 400800 and larger than $800 \mathrm{~cm} / \mathrm{s}^{2}$, the influence times are 30, 90 and 180 days, respectively (Nakata and Snieder 2012b; Wu and Peng 2012). Figure 2 shows an example of record selection for IBRH13. The total number of seismic records for IBRH11 is reduced from 1911 to 1113 after record selection. The number of seismic records with different rainfall classes for the selected seismic stations can be found in Table 3 .

\section{Seismic interferometry}

Both cross-correlation and deconvolution can be used to retrieve the Green's function representations 


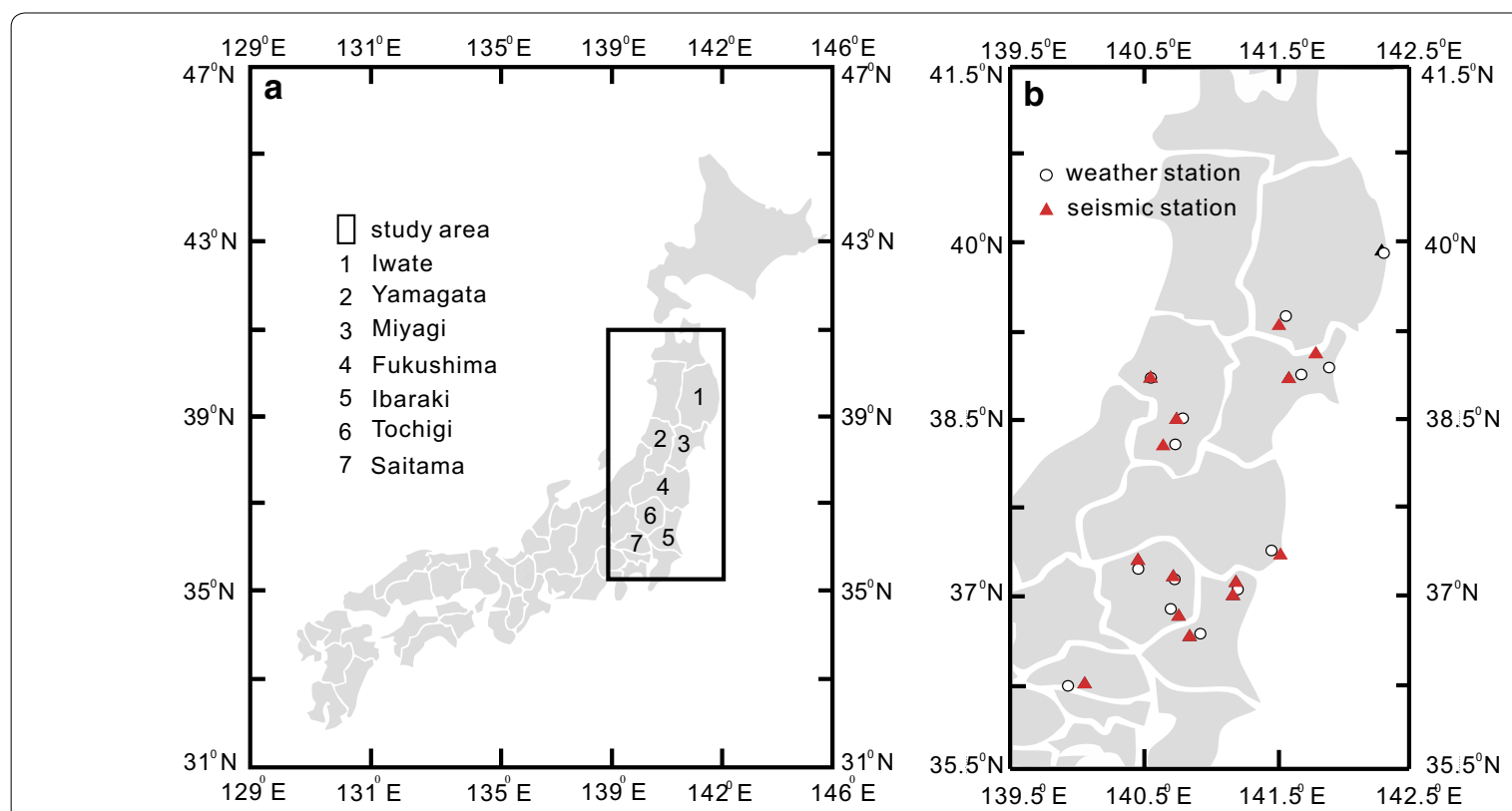

Fig. 1 a Study area. The selected seismic stations are distributed in seven prefectures of Northeast Honshu. $\mathbf{b}$ Magnification of the study area in Fig. 1a. The solid triangles represent the seismic stations, and the hollow circles represent the weather stations
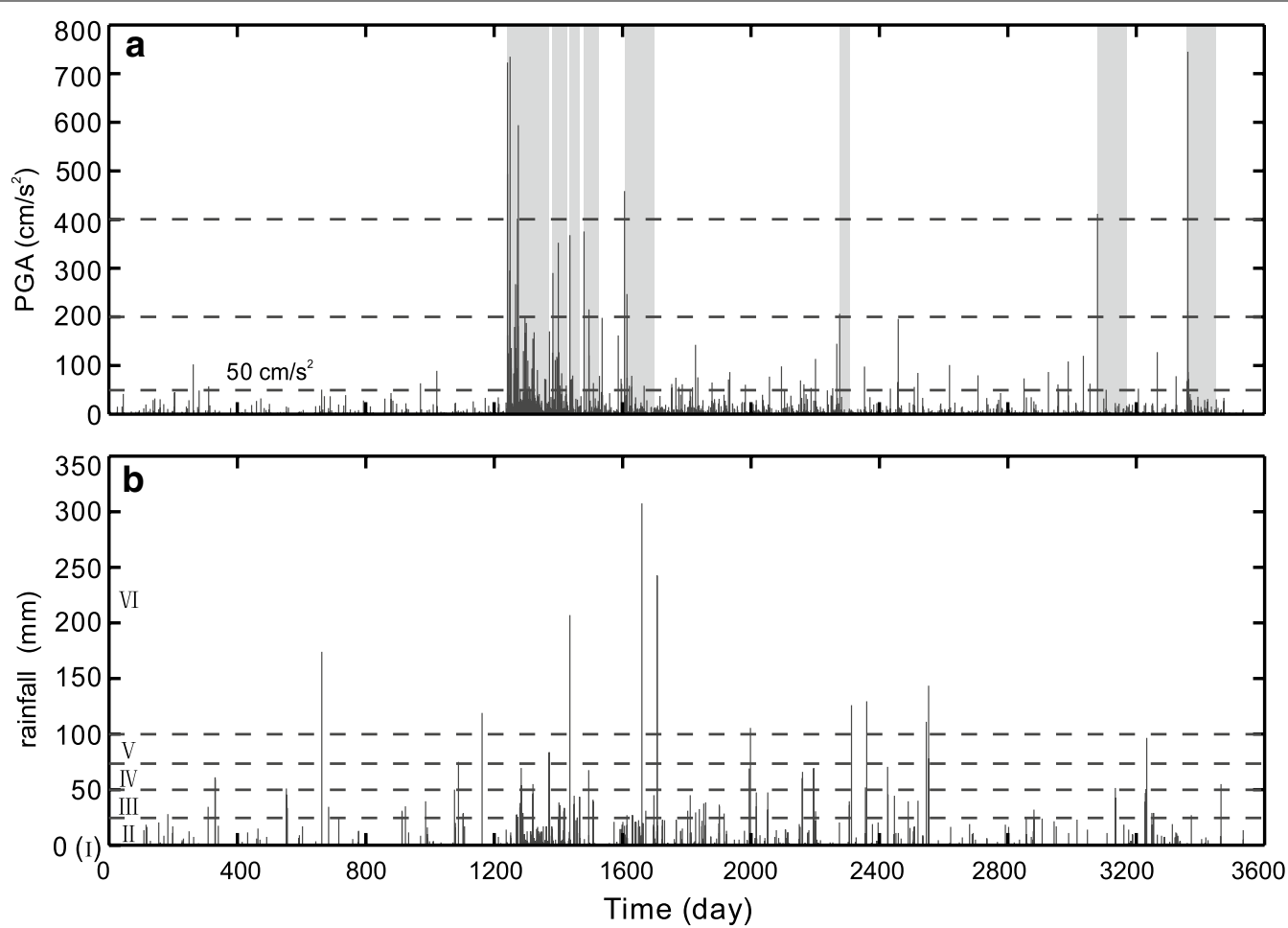

Fig. 2 a PGA of seismic records logged at IBRH13. The horizontal dashed lines represent 50,200 and $400 \mathrm{~cm} / \mathrm{s}^{2}$, respectively, and the gray areas represent the influence time of strong motions. b Daily rainfall for IBRH13. The horizontal dashed lines represent 25, 50 and $100 \mathrm{~mm}$, respectively. The zeroth day of the horizontal axis indicates the start date when sampling frequency of seismographs at IBRH13 is changed to $100 \mathrm{~Hz}(17 \mathrm{October}$ 2007) 
Table 3 Number of seismic records with different rainfall classes

\begin{tabular}{|c|c|c|c|c|c|c|c|}
\hline Station & I & II & III & IV & V & VI & Total \\
\hline FKSH14 & 1067 & 477 & 47 & 12 & 5 & 5 & 1613 \\
\hline IBRH11 & 978 & 373 & 55 & 6 & 4 & 4 & 1420 \\
\hline IBRH13 & 672 & 331 & 45 & 8 & 5 & 5 & 1066 \\
\hline IBRH14 & 705 & 369 & 58 & 15 & 4 & 5 & 1156 \\
\hline IWTH21 & 764 & 298 & 23 & 13 & 5 & 3 & 1106 \\
\hline IWTH26 & 667 & 418 & 32 & 7 & 2 & 2 & 1128 \\
\hline MYGH04 & 1013 & 378 & 31 & 8 & 7 & 3 & 1440 \\
\hline MYGH06 & 1148 & 416 & 24 & 5 & 3 & 2 & 1598 \\
\hline SITH06 & 580 & 219 & 21 & 2 & 1 & 3 & 826 \\
\hline TCGH10 & 1142 & 546 & 76 & 19 & 6 & 5 & 1794 \\
\hline TCGH16 & 1010 & 394 & 53 & 15 & 7 & 6 & 1485 \\
\hline TCGH17 & 343 & 247 & 17 & 5 & 0 & 2 & 619 \\
\hline YMTH03 & 259 & 227 & 5 & 0 & 2 & 2 & 497 \\
\hline YMTH07 & 640 & 567 & 20 & 9 & 0 & 2 & 1247 \\
\hline YMTH14 & 473 & 490 & 43 & 8 & 2 & 6 & 1022 \\
\hline
\end{tabular}

between different receiver locations in seismic interferometry. These two types of Green's function representation have been verified as effective methods for vertical array to extract shear wave velocity in many previous studies (Miyazawa et al. 2008; Nakata and Snieder 2012a; Takagi and Okada 2012). Moreover, Takagi and Okada (2012) reported that the cross-correlation of the coda waves is stable in time as the deconvolution of direct waves used by Nakata and Snieder (2012a). In this study, we preferred deconvolutionbased interferometry because it can eliminate the effect of the incident wavefields to get a more reasonable estimation of shear wave velocity (Nakata and Snieder 2012a). We also compared the results from coda waves and those from direct waves for three stations (i.e., IBRH11, IBRH13 and TCGH17) using deconvolutionbased interferometry as shown in Additional file 2: Fig. S2. It can be found that the results from coda waves are similar to those from direct waves, because deconvolution interferometry can eliminate the effects of the incident wavefields for vertical arrays as we mentioned above.

The deconvolution function in frequency domain can be calculated by Eq. (1) and it can be converted into time domain by inverse Fourier transform.

$$
G\left(\mathbf{r}_{\mathrm{s}}, \mathbf{s}, \omega\right)=\frac{u\left(\mathbf{r}_{\mathrm{s}}, \mathbf{s}, \omega\right)}{u\left(\mathbf{r}_{\mathrm{b}}, \mathbf{s}, \omega\right)} \approx \frac{u\left(\mathbf{r}_{\mathrm{s}}, \mathbf{s}, \omega\right) u^{*}\left(\mathbf{r}_{\mathrm{b}}, \mathbf{s}, \omega\right)}{\left|u\left(\mathbf{r}_{\mathrm{b}}, \mathbf{s}, \omega\right)\right|^{2}+\varepsilon}
$$

in which $s$ is source location, $u\left(\boldsymbol{r}_{\mathrm{b}}, \boldsymbol{s}, \omega\right)$ is the incoming wavefield recorded at the bottom sensor at location $\boldsymbol{r}_{\mathrm{b}}$, $u\left(\boldsymbol{r}_{\mathrm{s}}, \boldsymbol{s}, \omega\right)$ is the corresponding wavefield recorded at the surface sensor at location $\boldsymbol{r}_{\mathrm{s}}$, * is the complex conjugate and $\varepsilon$ is a regularization parameter, set as $1 \%$ of the average power spectrum of the borehole receiver (Nakata and Snieder 2012a), to enhance the stability of deconvolution function.

After computing deconvolution function, we grouped them by rainfall classes (Table 1 ) and then averaged them for each group. The shear wave velocities of different rainfall classes can be extracted using cubic spline interpolation to find peak times (Fig. 3b). These times are the travel times for shear waves that propagate between the bottom and surface sensors. By rotating the wavefields from $10^{\circ}$ to $180^{\circ}$ in $10^{\circ}$ interval, we computed the shear wave velocity as a function of polarization angle. As described in Nakata and Snieder (2012a), the velocity can be separated into the isotropic and the anisotropic terms by a Fourier series expansion. The anisotropic component of the velocity is caused by shear wave splitting, which is beyond the scope of this study. The isotropic component can be calculated by averaging velocities of the eighteen directions. We assumed the splitting time to be much smaller than the travel time, and employed the isotropic component to represent the near-surface velocity.

Figure 3 shows an example of deconvolution functions for the EW direction in different rainfall classes at TCGH17 station. The deconvolution functions have clear peaks near the measured travel times of shear wave based on velocity profiles. The peak time of the level VI lags $4.6 \mathrm{~ms}$ from that of level I (Fig. 3b). It could 

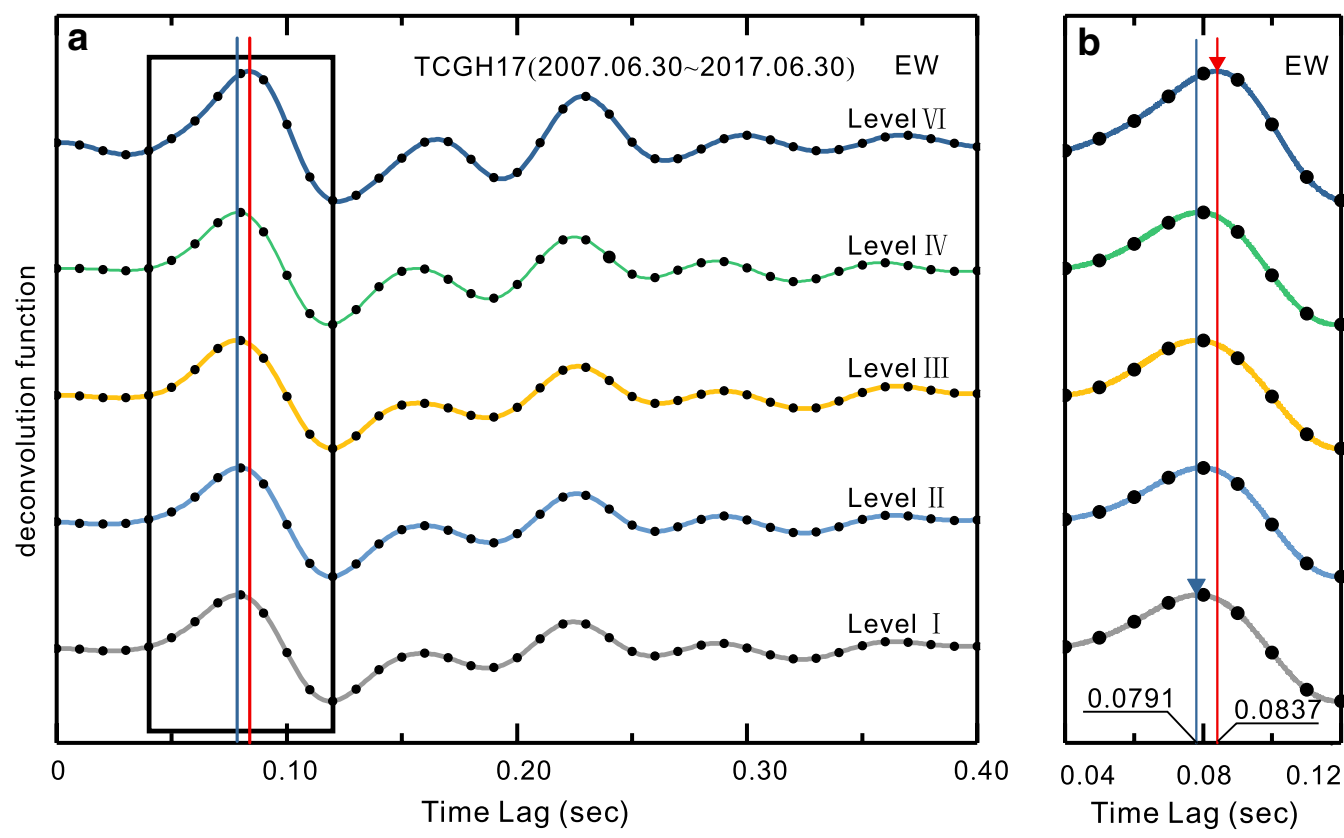

Fig. 3 a Deconvolution functions of different rainfall classes for the EW direction at TCGH17 station. Note that there is no seismic record with rainfall class $\vee$ at TCGH17 as shown in Table 3. b Enlargement of $\mathbf{a}$. The two vertical lines indicate the peak times of the deconvolution functions

be clearly observed that high-intensity rainfall has an obvious influence on near-surface shear wave velocity for TCGH17 station.

\section{Results}

We computed the shear wave velocities of different rainfall classes from deconvolution functions and calculated the relative velocity change $(\mathrm{d} v / \mathrm{v})$ for these 15 selected stations. The relative velocity change is defined as

$$
d v / v=\left(v_{i}-v_{\mathrm{I}}\right) / v_{\mathrm{I}}(i=\mathrm{II}, \mathrm{III}, \mathrm{IV}, \mathrm{V}, \mathrm{VI})
$$

in which $v_{i}$ is the near-surface shear wave velocity for level $i$.

Figure 4 depicts the relationship between the relative velocity change $\mathrm{d} v / v$ and the rainfall classes. It can be found that the results from averaged deconvolution function are comparable with the mean values of single measurements. Meanwhile, the relative high standard deviations of single measurements indicate the necessity of the averaging process. As discussed in Wang et al. (2017), seismic velocity changes in Japan are subjected to nonidentical environmental factors in different areas. According to local geological, climatic and geographical conditions, we infer that the seismic velocity variations in Northeast Honshu are mainly controlled by the strong motion, precipitation and sea level changes. It also should be noted that Northeast Honshu is one of the regions with the smallest seasonal seismic velocity changes in Japan, which allows detection of temporal change of seismic velocity associated with rainfall that might be masked by the strong seasonal perturbations in other areas.

It can be found that the surface shear wave velocities do not change obviously when rainfall class varies from level II to V, and the velocity decreases significantly when rainfall class reaches level VI. It can be concluded that there exists a threshold (rainfall class level VI) of the temporal influence of rainfall on near-surface shear wave velocity.

Nakata and Snieder (2012a) reported that the stations located at soft rock sites are influenced more by rainfall than the stations at hard rock sites. We followed the definition of the soft and hard rock sites of their study. The estimated shear wave velocity of hard rock sites is greater than $600 \mathrm{~m} / \mathrm{s}$, while that of soft rock sites is less than $600 \mathrm{~m} / \mathrm{s}$. Among the 15 stations, there are four stations (IBRH14, MYGH04, TCGH17 and YMTH03) are located at hard rock sites. However, in this study, it did not show that stations at soft rock sites are influenced more by rainfall than stations at hard rock sites. Moreover, the relative velocity change caused by high-intensity rainfall of TCGH17 station is much higher than that of 12 stations at soft rock sites (Fig. 4). One possible interpretation is that the relative velocity change $(\mathrm{d} v / v)$ highly depends on the borehole depth (Takagi and Okada 2012). More detailed explanation can be found in "Discussion" section. 


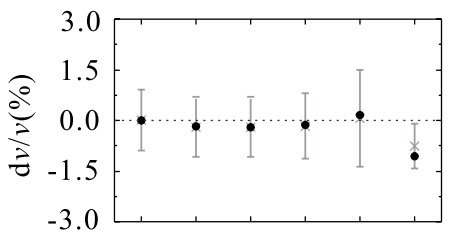

(1)FKSH14

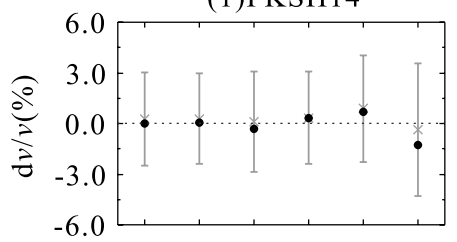

(4)IBRH14
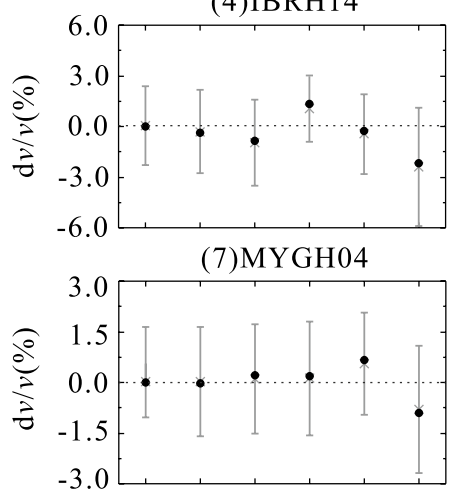

(10)TCGH10

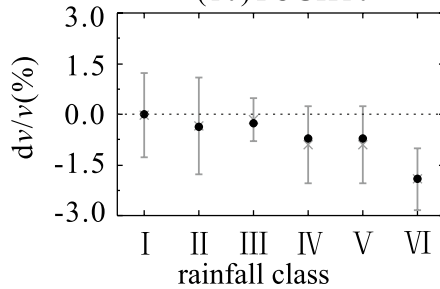

(13)YMTH03

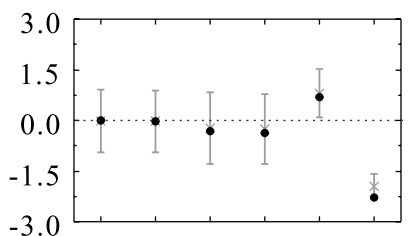

(2)IBRH11

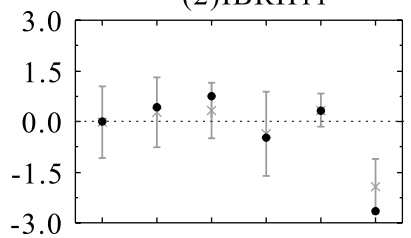

(5)IWTH21

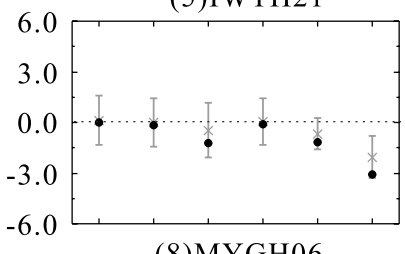

(8)MYGH06

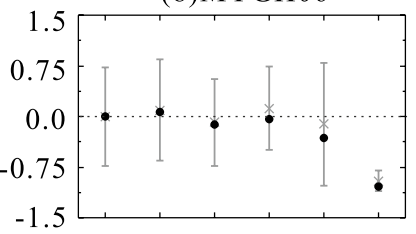

(11)TCGH16

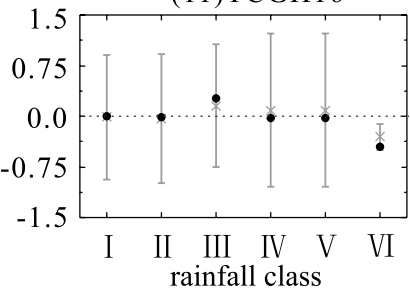

(14)YMTH07

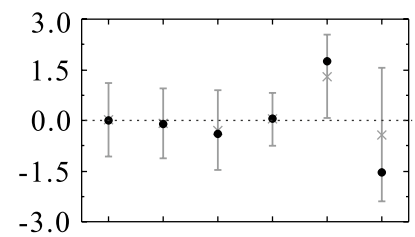

(3)IBRH13

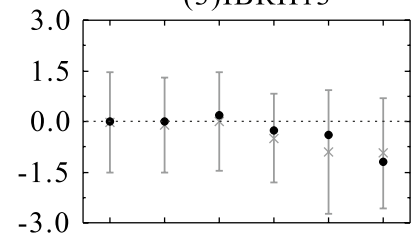

(6)IWTH26

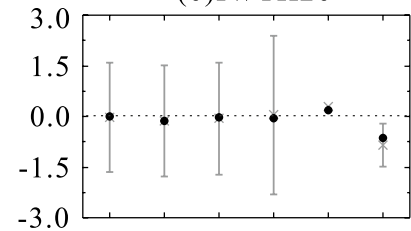

(9)SITH06

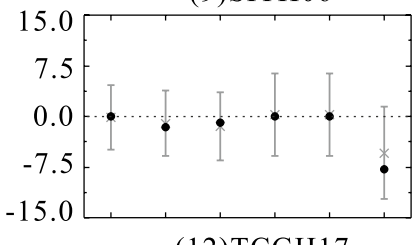

(12)TCGH17

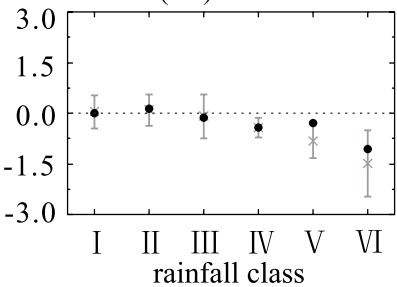

(15)YMTH14

Fig. 4 Relationships between the relative velocity change $d v / v$ and the rainfall classes for 15 seismic stations from KiK-net. The solid circular represents results from averaged deconvolution functions. The cross with error bar represents the mean value and the standard deviation of single measurements. The velocity does not change obviously when the rainfall class ranges from level II-V, while it is reduced by $1-10 \%$ when the rainfall class reaches level VI

\section{Discussion}

First, we discussed the threshold of the temporal influence of rainfall on the near-surface shear wave velocity. In a recent study, Dong and Lu (2016) used bender element technique to measure the dependencies of shear wave velocity on saturation for seven different types of unsaturated soils. They reported there are two thresholds of the influence of water content on shear wave velocity. The laboratory test results show that, as the volumetric water content varies from zero to the first threshold of around 0.15 , the shear wave velocities of different soils decrease sharply. When the water content is in the range of approximately $0.15-0.40$, the shear wave velocities gradually decrease with a mild rate as the water content increases. After the water content exceeds the second threshold of about 0.40 , the shear wave velocities decrease significantly with the water content increases. The velocity reduction is mainly caused by the decreased effective stress (Dong and Lu 2016; Snieder and Beukel 2004). The detailed properties of tested soils and the classifications can be found in Dong and Lu (2016).

Generally speaking, the initial water content of the in situ soil is higher than the first threshold. The water content of the surface sediment is influenced by rainfall directly, thus the relationship between near-surface velocity and rainfall is similar to that between shear wave velocity and water content. It is not difficult to understand the thresholds of rainfall for different stations are 
quite similar because thresholds of water content for different soils are about 0.4 , ranging from 0.35 to 0.45 .

Compared with wave velocity, wave slowness (the inverse of wave velocity) is a direct indicator of wave propagation time (the travel time is proportional to the wave slowness) mathematically, and has been widely used in geophysics and earthquake engineering (Boore and Asten 1983; Brown et al. 2002; Eisner et al. 2009; Hao and Stovas 2016; Steck 1995; Steck and Prothero 1993; Xiang et al. 1999). As shown in Fig. 5a, the threshold of the temporal influence of rainfall on near-surface shear wave velocity could be more clearly explained by the relationship between shear wave slowness and water content.

Since major velocity change is localized in shallow layer, the travel time increment is independent of the borehole depth. Thus we presented the relationship between travel time increment and rainfall class in Fig. 5b. Compared with the travel time corresponding to the rainfall class level I (no rain), the travel time increment is no more than $3 \times 10^{-4} \mathrm{~s}$ when rainfall class varies from level II to $\mathrm{V}$, and it ranges between $1 \times 10^{-3}$ and $7 \times 10^{-3} \mathrm{~s}$ (the mean value and standard deviation are $3.29 \times 10^{-3}$ and $1.36 \times 10^{-3} \mathrm{~s}$, respectively) when the rainfall class reaches level VI.

To get a deeper insight into the temporal influence of rainfall on near-surface shear wave velocity, we proposed a one-dimensional model to estimate travel time increments. As shown in Fig. 6, $P, H, \Delta \theta$ and $\Delta S$ are rainfall totals, permeate depth, the variation of surface volumetric water content and variation of shear wave slowness after rain, respectively. The travel time increment $\Delta t$ can be obtained as follows:

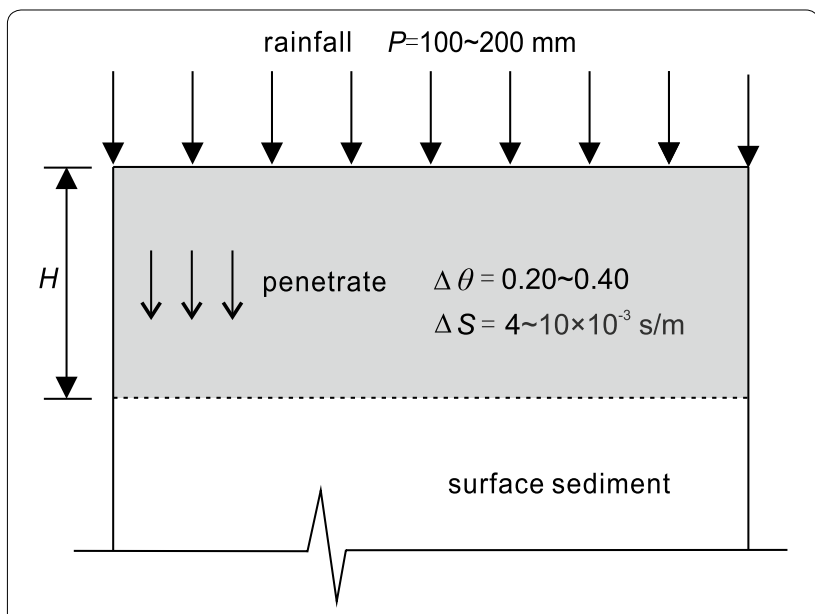

Fig. 6 One-dimensional model for estimating the travel time increment. From Fig. 5a, for a level VI rainfall with a rainfall total of about 100-200 mm, the variation of volumetric water content $\Delta \theta$ and variation of shear wave slowness $\Delta S$ can be estimated as approximately $20-40 \%$ and $4-10 \times 10^{-3} \mathrm{~s} / \mathrm{m}$, respectively

$$
\Delta t=\frac{H}{v_{2}}-\frac{H}{v_{1}}=H \cdot \Delta S
$$

in which $v_{1}$ and $v_{2}$ are surface shear wave velocities before and after rain, respectively. In the calculation model, we assumed the rainfall is completely and evenly absorbed by the surface sediments. Hence we can get:

$$
P=H \cdot\left(\theta_{2}-\theta_{1}\right)
$$
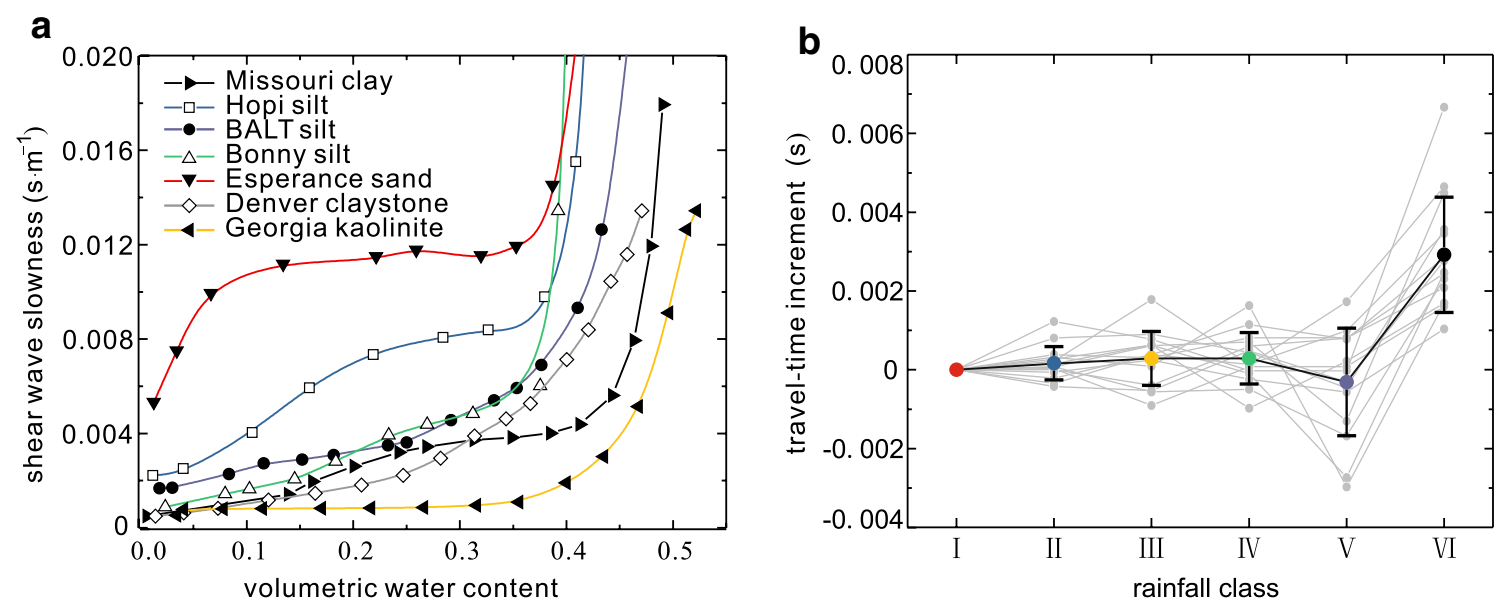

Fig. 5 (a) Relationships between shear wave slowness and volumetric water content for seven different types of soil (Dong and Lu, 2016). (b) Relationship between travel time increment and rainfall class for each seismic station (the gray lines). Black line represents cross-plot between the mean travel time increment and rainfall class with error bars. The relationship between shear wave slowness and volumetric water content has a similar pattern with that of travel time increment and rainfall class 
in which $\theta_{1}$ and $\theta_{2}$ are surface volumetric water content before and after rain, respectively. Combining Eqs. (3) and (4) yields:

$$
\begin{aligned}
H & =\frac{P}{\Delta \theta} \\
\Delta t & =\frac{P \cdot \Delta S}{\Delta \theta}
\end{aligned}
$$

Equations (5) and (6) can be used to estimate the permeate depth and the travel time increment, respectively. From Fig. 5a, when the rainfall class reaches level $\mathrm{VI}$, the variation of volumetric water content $\Delta \theta$ and variation of shear wave slowness $\Delta S$ can be estimated as approximately $20-40 \%$ and $4-10 \times 10^{-3} \mathrm{~s} / \mathrm{m}$, respectively. And the rainfall total of level VI is about 100-200 mm according to the meteorological records. Hence we can get $H=0.25-1.0 \mathrm{~m}$ and $\Delta t=1-10 \times 10^{-3} \mathrm{~s}$ for level VI. The result of $H$ is consistent with the previous analytical solutions for one-dimensional, transient infiltration (Srivastava and Yeh 1991) and it reveals that the temporal influence of rainfall on travel time increment is only related to surface sediments (around $1 \mathrm{~m}$, which is far less than the borehole depth). The estimated travel time increments are basically consistent with our results of observation (Fig. 5b), which validate the presented formula of Eq. (6).

\section{Conclusions}

In this study, we investigated temporal change of nearsurface shear wave velocity associated with rainfall using earthquake and weather logging data in Northeast Honshu. The relative velocity reduction is observed as several percent under high-intensity rainfall. The relationship between near-surface velocity and rainfall is similar to that between shear wave velocity and water content. Based on the results of observation, we proposed a onedimensional model to explain the temporal influence of rainfall on near-surface shear wave velocity. The conclusions of this study are summarized as follows:

1. The near-surface shear wave velocity does not change obviously under low-intensity rainfall, while it decreases significantly when the rainfall intensity exceeds a threshold (around $100 \mathrm{~mm}$ of $24 \mathrm{~h}$ rainfall total).

2. Compared with the travel time of no rain, the travel time increment of low-intensity rainfall is no more than $3 \times 10^{-4} \mathrm{~s}$, while that of high-intensity rainfall ranges between $1 \times 10^{-3}$ and $7 \times 10^{-3} \mathrm{~s}$ (mean value and standard deviation are $3.29 \times 10^{-3} \mathrm{~s}$ and $1.36 \times 10^{-3} \mathrm{~s}$, respectively).
3. The velocity change caused by rainfall is directly related to the dependency of velocity on saturation of surface sediments (around $1 \mathrm{~m}$ ). According to the one-dimensional model proposed in this study, the travel time increment can be estimated by multiplying rainfall $P$ and the ratio of the variation of the shear wave slowness $\Delta S$ to variation of volumetric water content $\Delta \theta$. This model can give a preliminary estimation of the temporal influence of rainfall on near-surface shear wave velocity.

\section{Additional files}

Additional file 1: Fig. S1. Relationships between the relative velocity change and the rainfall classes for different accumulated periods of rainfall amounts.

Additional file 2: Fig. S2. Relationships between the relative velocity change and the rainfall classes for direct waves and coda waves.

\section{Abbreviations}

CMA: China Meteorological Administration; JMA: Japan Meteorological Agency; NIED: National Research Institute for Earth Science and Disaster Resilience; PGA: Peak ground acceleration.

\section{Authors' contributions}

YM and YS participated in acquisition of seismic and meteorologic data. YS processed the obtained data. YS and SYW drafted the manuscript. YM, YS, and SYW contributed to the planning of this study and interpretation of the data.

All authors read and approved the final manuscript.

\section{Acknowledgements}

It is gratefully acknowledged that NIED and JMA provided the earthquake and weather data, respectively.

\section{Competing interests}

The authors declare that they have no competing interests.

\section{Availability of data and materials}

The earthquake and weather data were provided by National Research Institute for Earth Science and Disaster Prevention and Japan Meteorological Agency, respectively. The earthquake records are available on http://www. kyoshin.bosai.go.jp/kyoshin/quick/index_en.html. The weather records are available on http://www.data.jma.go.jp/obd/stats/etrn/index.php.

\section{Consent for publication}

Not applicable.

Ethics approval and consent to participate

Not applicable.

\section{Funding}

This study was financially supported by the National Key R\&D Program of China (No. 2016YFC0800200), the National Science Foundation of China (No. 51778260), and the China Postdoctoral Science Foundation (No. 2018M642845).

\section{Publisher's Note}

Springer Nature remains neutral with regard to jurisdictional claims in published maps and institutional affiliations. 
Received: 30 August 2018 Accepted: 4 December 2018 Published online: 22 December 2018

\section{References}

Ahmadi MM, Paydar NA (2014) Requirements for soil-specific correlation between shear wave velocity and liquefaction resistance of sands. Soil Dyn Earthq Eng 57(2):152-163. https://doi.org/10.1016/j.soild yn.2013.11.001

Aoi S, Kunugi T, Fujiwara H (2004) Strong-motion seismograph network operated by NIED: K-net and KiK-net. J Jpn Assoc Earthq Eng 4(3):65-74. https ://doi.org/10.5610/jaee.4.3_65

Bakulin A, Calvert R (2006) The virtual source method: theory and case study. Geophysics 71(4):SI139-SI150. https://doi.org/10.1190/1.2216190

Boore DM, Asten MW (1983) Comparisons of shear-wave slowness in the Santa Clara Valley, California, using blind interpretations of data from invasive and noninvasive methods. Bull Seismol Soc Am 98(4):1983-2003. https:// doi.org/10.1785/0120070277

Borcherdt RD (1994) Estimates of site-dependent response spectra for design (methodology and justification). Earthq Spectra 10(4):617-653. https:// doi.org/10.1193/1.1585791

Brenguier F, Shapiro NM, Campillo M, Ferrazzini V, Duputel Z, Coutant O et al (2008) Towards forecasting volcanic eruptions using seismic noise. Transl World Seismol 1(2):126-130. https://doi.org/10.1038/ngeo104

Brenguier F, Clarke D, Aoki Y, Shapiro NM, Campillo M, Ferrazzini V (2011) Monitoring volcanoes using seismic noise correlations. CR Geosci 343(8):633638. https://doi.org/10.1016/j.crte.2010.12.010

Brenguier F, Campillo M, Takeda T, Aoki Y, Shapiro NM, Briand X, Emoto K, Miyake $H$ (2014) Mapping pressurized volcanic fluids from induced crustal seismic velocity drops. Science 345(6192):80-82. https://doi. org/10.1126/science.1254073

Brown LT, Boore DM, Stokoe KH (2002) Comparison of shear-wave slowness profiles at 10 strong-motion sites from noninvasive SASW measurements and measurements made in boreholes. Bull Seismol Soc Am 92(8):31163133. https://doi.org/10.1785/0120020030

Clements T, Denolle MA (2018) Tracking groundwater levels using the ambient seismic field. Geophys Res Lett 45(13):6459-6465. https://doi. org/10.1029/2018GL077706

Choi Y, Stewart JP (2005) Nonlinear site amplification as function of $30 \mathrm{~m}$ shear wave velocity. Earthq Spectra 21(1):1-30. https://doi.org/10.1193/1.18565 35

Dong Y, Lu N (2016) Dependencies of shear wave velocity and shear modulus of soil on saturation. J Eng Mech 142(11):4016083. https://doi. org/10.1061/(ASCE)EM.1943-7889.0001147

Eisner L, Fischer T, Rutledge JT (2009) Determination of S-wave slowness from a linear array of borehole receivers. Geophys J R Astron Soc 176(1):31-39. https://doi.org/10.1111/j.1365-246X.2008.03939.x

Hao Q, Stovas A (2016) P-wave slowness surface approximation for tilted orthorhombic media. Geophysics 81(3):C99-C112. https://doi. org/10.1190/GEO2015-0440.1

Hardin BO, Black WL (1968) Closure on vibration modulus of normally consolidated clay. J Soil Mech Found Div 94(2):353-370

Hillers G, Campillo M (2016) Fault zone reverberations from cross-correlations of earthquake waveforms and seismic noise. Geophys J Int 204(3):15031517. https://doi.org/10.1093/gji/ggv515

Hillers G, Campillo M, Ma KF (2014) Seismic velocity variations at TCDP are controlled by MJO driven precipitation pattern and high fluid discharge properties. Earth Planet Sci Lett 391(2):121-127. https://doi.org/10.1016/j. epsl.2014.01.040

Hillers G, Benzion Y, Campillo M, Zigone D (2015a) Seasonal variations of seismic velocities in the San Jacinto Fault area observed with ambient seismic noise. Geophys J Int 202(2):920-932. https://doi.org/10.1093/gji/ ggv151

Hillers G, Retailleau L, Campillo M, Inbal A, Ampuero JP, Nishimura T (2015b) In situ observations of velocity changes in response to tidal deformation from analysis of the high-frequency ambient wavefield. J Geophys Res Solid Earth 120(1):210-225. https://doi.org/10.1002/2014JB011318

Hobiger M, Wegler U, Shiomi K, Nakahara H (2012) Coseismic and postseismic elastic wave variations caused by the 2008 Iwate-Miyagi Nairiku earthquake, Japan. J Geophys Res Solid Earth 117(B9):B09313. https://doi. org/10.1029/2012jb009402

Lee CJ, Hung WY, Tsai CH, Chen T, Tu Y, Huang CC (2014) Shear wave velocity measurements and soil-pile system identifications in dynamic centrifuge tests. Bull Earthq Eng 12(2):717-734. https://doi.org/10.1007/s1051 8-013-9545-1

Mainsant G, Larose E, Brönnimann C, Jongmans D, Michoud C, Jaboyedoff M (2012) Ambient seismic noise monitoring of a clay landslide: toward failure prediction. J Geophys Res Earth Surf 117:F01030. https://doi. org/10.1029/2011JF002159

Mehta K, Snieder R, Graizer V (2007) Extraction of near-surface properties for a lossy layered medium using the propagator matrix. Geophys J Int 169(1):271-280. https://doi.org/10.1111/j.1365-246X.2006.03303.x

Meier U, Shapiro NM, Brenguier F (2010) Detecting seasonal variations in seismic velocities within Los Angeles basin from correlations of ambient seismic noise. Geophys J Int 181(2):985-996. https://doi.org/10.1111/ j.1365-246x.2010.04550.x

Miyazawa M, Snieder R, Venkataraman A (2008) Application of seismic interferometry to extract $\mathrm{P}$ - and S-wave propagation and observation of shearwave splitting from noise data at Cold Lake, Alberta, Canada. Geophysics 73(4):D35-D40. https://doi.org/10.1190/1.2937172

Nakata N, Snieder R (2011) Near-surface weakening in Japan after the 2011 Tohoku-Oki earthquake. Geophys Res Lett 38(17):L17302. https://doi. org/10.1029/2011GL048800

Nakata N, Snieder R (2012a) Estimating near-surface shear wave velocities in Japan by applying seismic interferometry to KiK-net data. J Geophys Res Solid Earth 117(B1):B01308. https://doi.org/10.1029/2011JB008595

Nakata N, Snieder R (2012b) Time-lapse change in anisotropy in Japan's near surface after the 2011 Tohoku-Oki earthquake. Geophys Res Lett 39(11):L11313. https://doi.org/10.1029/2012GL051979

Niu F, Silver PG, Daley TM, Cheng X, Majer EL (2008) Preseismic velocity changes observed from active source monitoring at the Parkfield SAFOD drill site. Nature 454(7201):204-208. https://doi.org/10.1038/nature07111

Obermann A, Planès T, Larose E, Campillo M (2013) Imaging preeruptive and coeruptive structural and mechanical changes of a volcano with ambient seismic noise. J Geophys Res Solid Earth 118(12):6285-6294. https://doi. org/10.1002/2013JB010399

Ohmi S, Hirahara K, Wada H, Ito K (2008) Temporal variations of crustal structure in the source region of the 2007 Noto Hanto Earthquake, central Japan, with passive image interferometry. Earth Planets Space 60(10):1069-1074. https://doi.org/10.1186/BF03352871

Okada Y, Kasahara K, Hori S, Obara K, Sekiguchi S, Fujiwara H et al (2004) Recent progress of seismic observation networks in Japan-Hi-net, F-net, K-net and KiK-net. Earth Planets Space 56(8):xv-xxviii. https://doi. org/10.1186/BF03353076

Pilz M, Parolai S, Bindi D, Saponaro A, Abdybachaev U (2014) Combining seismic noise techniques for landslide characterization. Pure Appl Geophys 171(8):1729-1745. https://doi.org/10.1007/s00024-013-0733-3

Richter T, Sen-Schönfelder C, Kind R, Asch G (2014) Comprehensive observation and modeling of earthquake and temperature-related seismic velocity changes in Northern Chile with passive image interferometry. J Geophys Res Solid Earth 119(6):4747-4765. https://doi.org/10.1002/2013 B010695

Rivet D, Brenguier F, Cappa F (2015) Improved detection of preeruptive seismic velocity drops at the Piton de La Fournaise volcano. Geophys Res Lett 42(15):6332-6339. https://doi.org/10.1002/2015GL064835

Sen-Schönfelder C, Wegler U (2006) Passive image interferometry and seasonal variations of seismic velocities at Merapi volcano, Indonesia. Geophys Res Lett 33(21):L21302. https://doi.org/10.1029/2006GL027797

Snieder R, Beukel AVD (2004) The liquefaction cycle and the role of drainage in liquefaction. Granul Matter 6(1):1-9. https://doi.org/10.1007/s1003 5-003-0151-9

Srivastava R, Yeh TCJ (1991) Analytical solutions for one-dimensional, transient infiltration toward the water table in homogeneous and layered soils. Water Resour Res 27(5):753-762

Steck LK (1995) Simulated annealing inversion of teleseismic P-wave slowness and azimuth for crustal velocity structure at Long Valley Caldera. Geophys Res Lett 22(4):497-500. https://doi.org/10.1029/94GL03050

Steck LK, Prothero WA (1993) Observations of direct P-wave slowness and azimuth anomalies for teleseisms recorded in Long Valley Caldera, California. Bull Seismol Soc Am 83(5):1391-1419 
Takagi R, Okada T (2012) Temporal change in shear velocity and polarization anisotropy related to the 2011 M9.0 Tohoku-Oki earthquake examined using KiK-net vertical array data. Geophysical Research Letters 39(9):L09310. https://doi.org/10.1029/2012GL051342

Toksoz MN, Cheng CH, Timur A (1976) Velocities of seismic waves in porous rocks. Geophysics 41(4):621-645. https://doi.org/10.1190/1.1440639

Tsai VC (2011) A model for seasonal changes in GPS positions and seismic wave speeds due to thermoelastic and hydrologic variations. J Geophys Res Solid Earth 116(B4):B04404. https://doi.org/10.1029/2010JB008156

Voisin C, Guzmán MAR, Réfloch A, Taruselli M, Garambois S (2017) Groundwater monitoring with passive seismic interferometry. J Water Resour Prot 09(12):1414-1427. https://doi.org/10.4236/jwarp.2017.912091

Wang Q-Y, Brenguier F, Campillo M, Lecointre A, Takeda T, Aoki Y (2017) Seasonal crustal seismic velocity changes throughout Japan. J Geophys Res Solid Earth 122(10):7987-8002. https://doi.org/10.1002/2017JB014307

Wegler U, Sens-Schönfelder C (2010) Fault zone monitoring with passive image interferometry. Geophys J R Astron Soc 168(3):1029-1033. https:// doi.org/10.1111/j.1365-246X.2006.03284.X
Wegler U, Lühr BG, Snieder R, Ratdomopurbo A (2006) Increase of shear wave velocity before the 1998 eruption of Merapi volcano (Indonesia). Geophys Res Lett 33(9):L09303. https://doi.org/10.1029/2006GL025928

Wu C, Peng Z (2012) Long-term change of site response after the Mw, 9.0 Tohoku earthquake in Japan. Earth Planets Space 64(12):1259-1266. https ://doi.org/10.5047/eps.2012.05.012

Xiang D, Hsu NN, Blessing GV (1999) Imaging of acoustic surface wave slowness. Appl Phys Lett 74(15):2236-2238. https://doi.org/10.1063/1.123812

Xu X, Su L, Zhang G, Zhu H (2017) Analysis on shear wave velocity structure of a gravel landslide based on dual-source surface wave method. Landslides 14(3):1127-1137. https://doi.org/10.1007/s10346-016-0780-9

Yamada M, Mori J, Ohmi S (2010) Temporal changes of subsurface velocities during strong shaking as seen from seismic interferometry. J Geophys Res 115(B3):B03302. https://doi.org/10.1029/2009JB006567

\section{Submit your manuscript to a SpringerOpen ${ }^{\odot}$ journal and benefit from:}

- Convenient online submission

- Rigorous peer review

- Open access: articles freely available online

- High visibility within the field

- Retaining the copyright to your article

Submit your next manuscript at $\gg$ springeropen.com 